\title{
Formação continuada de professores de Ciências: um tema sempre atual e relevante
}

A formação de professores, tanto inicial como continuada, tem sido uma preocupação dos pesquisadores em Educação para a Ciência. Para esses pesquisadores, é necessário que o conhecimento originário desses estudos esteja presente e, também, exerça influência nos cursos de formação. É necessário não apenas capacitar, mas, também, formar profissionais capazes de atuarem política e socialmente na formação dos alunos, construindo assim a ação educativa em sua totalidade (SOARES, 2007).

Os cursos de formação inicial, de acordo com Cachapuz et al. (2011), mostram uma insuficiência devido à separação entre os conteúdos científicos e os pedagógicos, indicando a necessidade de um tratamento global e integrado dos problemas que se colocam no processo de ensino-aprendizagem de Ciências.

$\mathrm{Na}$ literatura constatamos que são relatadas inúmeras lacunas na formação inicial e pouca contribuição dos cursos de formação continuada na mudança da prática docente empregada no ensino de Ciências, principalmente nos conteúdos relacionados à Física (FREITAS e VILLANI, 2002; CACHAPUZ et al., 2011; CARVALHO, 2004; CARVALHO et al., 2011).

Zimmermann e Bertani (2007) argumentam, sobre os Cursos de Formação inicial de Professores de Ciências e Matemática, que esses apresentam antigos problemas, dentre eles, a desarticulação entre as disciplinas e entre teoria e prática, que se refletem na construção do perfil do futuro professor. Assim, faz-se necessária uma nova forma de pensar e estruturar os cursos de formação docente.

Devido ao grande número de problemas, já evidenciados nas investigações aqui apresentadas, sobre a formação inicial de professores, atribuímos fundamental importância aos cursos de Formação Continuada como forma de minimizar esses problemas. Acreditamos que os cursos formação continuada de professores de Ciências devem articular a teoria e a prática em situações reais com as quais o professor tenha vivenciado ou vai se deparar em sala de aula e, também, propor situações que permitam ao docente superar dificuldades conceituais e desenvolver, gradativa e continuamente, segurança para elaborar e executar atividades experimentais.

Para Carvalho e Gil-Pérez (2011) a formação de professores não consiste no treinamento de uma série de competências, mas na preparação para que, em um dado contexto, tomem decisões fundamentadas. Tal preparação torna-se particularmente necessária quando o papel do professor deixa de ser o de simples transmissor de conhecimentos para se transformar em orientador das 
atividades dos alunos. O professor deve desempenhar o papel de mediador. Ele deve levar em conta que precisa utilizar sempre um vocabulário vasto, além de usar nomenclaturas corretas e dar explicações coerentes, que satisfaçam o grau de desenvolvimento dos alunos.

Ainda segundo Carvalho e Gil-Péres (ibid), os professores em cursos de formação constroem visões sobre ensino e aprendizagem dos conceitos de Física na disciplina de Ciências. Tais visões são fortemente influenciadas pelas concepções e habilidades previamente construídas, tanto sobre o conteúdo disciplinar, quanto sobre aprendizagem. Essas convicções podem conflitar com o que está sendo apreendido, constituindo-se um fator de resistência à aprendizagem significativa. Por esse motivo, é fundamental, que o formador de professores busque situações reais que coloquem essas convicções em conflito e ele não consiga responder com o seu conhecimento atual.

Como qualquer educador, o formador de professores traz para a sua prática crenças, experiências pessoais e modelos incorporados ao longo de sua própria formação e de sua caminhada como profissional. Desse modo, ao atuar, o formador mobiliza um conjunto de saberes próprios que, explícita ou implicitamente, gera impacto sobre os professores em formação (ALTARUGIO e VILLANI, 2010).

Em 2002, Freitas e Villani (2002), analisando os programas de capacitação de professores em exercício, verificaram que a construção dos conhecimentos que orientam os projetos de inovação continuam ocorrendo no exterior do "mundo dos professores e das salas de aulas". Esses conhecimentos, considerados de maior status que o saber da experiência dos professores, continuam sendo impingidos pelos movimentos de inovação no ensino, de forma paradoxal aos seus preceitos, ou seja, dentro dos moldes da racionalidade técnica.

Dessa forma, professores são concebidos como consumidores de conhecimentos e os programas de capacitação são, normalmente, pensados como treinamento de professores para a correta implementação dos conhecimentos produzidos por outros indivíduos mais experientes (FREITAS e VILLANI, 2002).

Corroborando com a percepção de Freitas e Villani (2002), podemos nos basear ainda nos estudos de António Nóvoa, onde a formação docente é ponto central de uma perspectiva de construção permanente do professor, considerando sua prática.

A formação não se constrói por acumulação (de cursos, de conhecimentos ou de técnicas), mas sim através de um trabalho de reflexividade crítica sobre as práticas e de (re)construção permanente de uma identidade pessoal. Por isso é tão importante investir na pessoa e dar estatuto ao saber da experiência. (Nóvoa, 1995, p.25).

Devemos também aqui salientar a questão dos Mestrados Profissionais, principalmente na área de Ensino, como uma nova perspectiva no que se refere à formação continuada de professores. Na área do ensino, os mestrados profissionais já superam em quantidade os mestrados acadêmicos, sendo hoje 82 Mestrados Profissionais e 70 Mestrados Acadêmicos. O mestrado em ensino, por exigir a apresentação de um produto do mestrado, tem sido efetivamente importante para o desenvolvimento de tecnologias educacionais que podem promover mudanças na atuação docentes, pois partem de problemas reais da sala de aula, e buscam alternativas para o enfrentamento destas situações, com base em trabalhos sólidos de pesquisa, fundamentados e com retorno direto para a comunidade. Entendemos que esta é uma oportunidade, entretanto, corroboramos com Ostermann e Rezende 
(2015), por entender que nesta modalidade a capacitação em atividade pode ser vista como uma forma mais barata e efetiva para a formação continuada de professores, e parte de uma demanda internacional por melhoria de índices de qualidade na educação, colocando boa parte da responsabilidade pela melhoria da educação para os professores. Para Ostermann e Rezende (2015)

Tais concepções encontram-se, em grande parte, naturalizadas nas políticas educacionais recentes e na literatura sobre a formação docente publicada no Brasil e em outros países, reforçando, também, a ideia de que os professores nunca estão preparados e precisam ser constantemente (re)formados e avaliados. Como consequência, em diferentes países, tem sido priorizada a prestação de contas do professor e propostas políticas que diferenciam salários de acordo com um suposto mérito mensurado por avaliações externas (OSTERMANN e REZENDE, 2015)

Portanto, numa perspectiva de formação continuada que efetivamente possa dar retorno para as ações do dia-a-dia da sala de aula, é necessário construir um processo de formação continuada de longa duração, em conjunto com o professor e com a escola, com trabalho coletivo e que deem voz aos participantes, buscando motivá-los, apesar das condições sociais, políticas, econômicas que perpassam a sua prática pedagógica. Sendo assim, precisa ser um processo contínuo, integrado ao dia-a-dia do professor e da escola. Dessa maneira, a evasão é diminuída drasticamente e aumentam as chances desses professores realmente reformularem suas práticas docentes, na medida em que se tornam corresponsáveis no processo de formação continuada.

Acreditamos ser importante que os professores percebam que as Ciências têm importância fundamental no processo de formação social e cultural dos indivíduos, tendo que ultrapassar o limite da informação para atingir o de formação.

Concluindo, é importante destacar que a formação continuada tem, entre outros objetivos, propor novas metodologias e colocar os professores em contato com as discussões teóricas atuais, com a intenção de contribuir para as mudanças que se fazem necessárias para a melhoria da ação pedagógica na escola. É certo que conhecer novas práticas faz parte do processo de construção profissional, mas não bastam, se estas não possibilitam ao professor relacioná-las com seu conhecimento prático construído no seu cotidiano.

Nelson Luiz Reyes Marques ${ }^{1}$ Marcos André Betemps Vaz da Silva²

\footnotetext{
1, 2 IFSul - Instituto Federal de Educação, Ciência e Tecnologia Sul-rio-grandense, Pelotas/RS - Brasil.
} 


\section{REFERÊNCIAS}

ALTARUGIO M. H. e VILLANI, A. O papel do formador no processo reflexivo de professores de Ciências. Investigações em Ensino de Ciências, V15(2), pp. 385-401, 2010.

CACHAPUZ, A., GIL-PÉREZ, D., CARVALHO, A. M. P., PRAIA, J. e VILCHES, A. A necessária renovação no Ensino de Ciências. 2. Ed. São Paulo: Cortez, 2011.

CACHAPUZ, A., GIL-PÉREZ, D., CARVALHO, A. M. P., PRAIA, J. e VILCHES, A. A necessária renovação no Ensino de Ciências. 2. Ed. São Paulo: Cortez, 2011.

CARVALHO, A. M. Critérios estruturantes para o Ensino de Ciências. In: Carvalho, A. M. P. Ensino de Ciências - Unindo a Pesquisa e a Prática. São Paulo: Pioneira Thonson Learning, 2004.

CARVAlho, A. M. P. e GIL-PÉREZ, D. A Formação do Professor de Ciências. 10. Ed. São Paulo: Cortez, 2011.

FREITAS, D. e VILLANI, A. Formação de professores de ciências: um desafio sem limites. Investigações em Ensino de Ciências, v. 7, n. 3., 2002.

NÓVOA, A. Profissão professor. Porto: Porto Editora, 1995

OSTERMANN, F. e REZENDE, F. Os mestrados profissionais em ensino das ciências da natureza no Brasil. Ciênc. educ. (Bauru), Bauru, v. 21, n. 3, p. I-III, set. 2015. Disponível em $<$ http://www.scielo.br/scielo.php?script=sci_arttext\&pid=S1516-

$73132015000300001 \&$ lng=pt\&nrm=iso>. acesso em 20 jul. 2017.

SOARES, M. As pesquisas nas áreas específicas influenciando o curso de formação de professores. In: ANDRÉ, M. (Org.) 0 papel da pesquisa na formação e na prática dos professores. Campinas: Papirus, 2007. p. 91-105.

ZIMMERMANN, E. e BERTANI, P. C. Q. Um novo olhar sobre os cursos de formação de professores. Caderno Brasileiro de Ensino de Física, v. 20, n. 1: p. 43-62, abr. 2003. 